\title{
New combinations of Afrotropical Chironomini (Diptera: Chironomidae)
}

\author{
Torbjørn Ekrem \& Elisabeth Stur \\ Norwegian University of Science and Technology, NTNU University Museum, Department of Natural His- \\ tory,NO-7491 Trondheim,Norway.Email:torbjorn.ekrem@ntnu.no,elisabeth.stur@ntnu.no
}

http://zoobank.org/34577945-4965-42A4-A9D9-1AF78CE58181

\begin{abstract}
During our work on the Chironomidae chapter of the forthcoming Manual of Afrotropical Diptera we examined type material of the four Chironomini species Chironomus (Endochironomus) hamatus, Chironomus (E.) pruinosus, Chironomus (E.) woodi and Chironomus (Cryptochironomus) inflexus described by Paul Freeman. We provide photos of the types and associated material and argue for the following generic placements: Chironomus (Benthalia) hamatus comb.n., Kiefferulus pruinosus comb. n., Synendotendipes woodi comb. n. and Cladopelma inflexum.
\end{abstract}

\section{Introduction}

Paul Freeman contributed considerably to the knowledge of Afrotropical Chironomidae through his four monographs on Chironomidae south of the Sahara (Freeman 1955, Freeman 1956, Freeman 1957, Freeman 1958). These contributions from the 1950s summarized the contemporary knowledge of Afrotropical Chironomidae and provided an excellent basis for future work and revisions. A number of species new to science were described by Freeman in these and subsequent works, and Freeman still holds the authorship for almost 30\% of all the currently known species from the Afrotropical Region. Later taxonomic revisions have changed the generic placement of 80 species, but more than 90 species retain Freeman's original generic assignments. It should be noted that Freeman's original descriptions were based on adult morphology only; contemporary generic assignments can be enhanced by descriptions of immature stages as well as use of molecular taxonomic techniques.

A large initiative to publish a Manual of Afrotropical Diptera was initiated by Ashley Kirk-Spriggs and officially launched at the 7th International Congress of Dipterology, San José, Costa Rica in 2010 (http://afrotropicalmanual.org). As part of our work on the chapter of Afrotropical Chironomidae (Ekrem et al. in press), type material of four Chironomini species described by Freeman were examined to re-evaluate the generic placement: Chironomus (Cryptochironomus) inflexus Freeman, 1957; Chironomus (Endochironomus) hamatus Freeman, 1957; Chironomus (Endochironomus) pruinosus Freeman, 1961 and Chironomus (Endochironomus) woodi Freeman, 1957. These species were specifically selected for evaluation as they were particuarly difficult to classify under current generic concepts.

\section{Material and methods}

Nominal types as well as other material were sought in the Natural History Museum, London, UK (NHMUK), Muséum national d'Histoire naturelle, Paris, France (MNHN), and the Department of Natural History, University Museum of Bergen, Bergen, Norway (ZMBN). Most of the specimens were already mounted on slides when we received them, but the holotype of Chironomus (Endochironomus) pruinosus was mounted in Euparal by us according to the procedure described by Pinder (1989).

The literature consulted to evaluate and confirm generic placements included works by Sæther (1977a), Sæther (1977b), Grodhaus (1987), Cranston et al. (1989) and Yan et al. (2008). Morphological terminology follows Sæther (1980).

Digital photographs were taken with a Leica DFC420 camera mounted on a Leica DM6000 $\mathrm{B}$ compound microscope using bright field or Nomarski DIC and the software Leica Application Suite.

\section{Results and discussion}

Chironomus (Benthalia) hamatus (Freeman, 1957) comb. $\mathbf{n}$.

http://zoobank.org/F9A669AB-EE75-4C5AABB5-C58DA7091109

Chironomus (Endochironomus) hamatus Freeman, 1957: 355.

Endochironomus hamatus (Freeman, 1957), Freeman and Cranston (1980). 
Material examined: 1 paratype male (NHMUK), Democratic Republic of the Congo, Elisabethville, 30.iii.1939, H.-J. Brédo.

The examined male paratype shows characters typical of the Chironomus group of genera: antenna with 11 flagellomeres, medially fused antepronotal lobes, inferior volsella subcylindrical with dense apical setae. Unfortunately, the slide-mounted hypopygium (Figs 1a, b) is quite distorted, but the almost parallel-sided gonostylus without subapical constriction, anal tergite bands that meet medially in front of and not encircling median tergite setae, and the shape of the superior volsella resembles what is known from Benthalia Lipina (Shilova 1980 sub Einfeldia carbonaria (Meigen, 1804), Sæther 2012). Moreover, the specimen has large barrel-shaped frontal tubercles (Figs 1c, d) characteristic of Benthalia (Shilova 1980, fig. 8A 2 ). In addition there is a smaller pair of warts on the anterior part of vertex, dorsolaterally with respect to the frontal tubercles. A similar arrangement has been recorded for Tanytarsus epleri Ekrem et al., 2003. For this species the pupa has large frontal warts in addition to enlarged frontal tubercles (Ekrem et al. 2003), thus similar structures might be present in the unknown pupa of Chironomus (B.) hamatus.

Some authors regard Benthalia a separate genus (e.g. Sæther and Spies 2013, Yamamoto and Yamamoto 2014), while Epler et al. (2013) regard Benthalia as possible subgenus of Chironomus Meigen along with Fleuria Kieffer, Baeotendipes

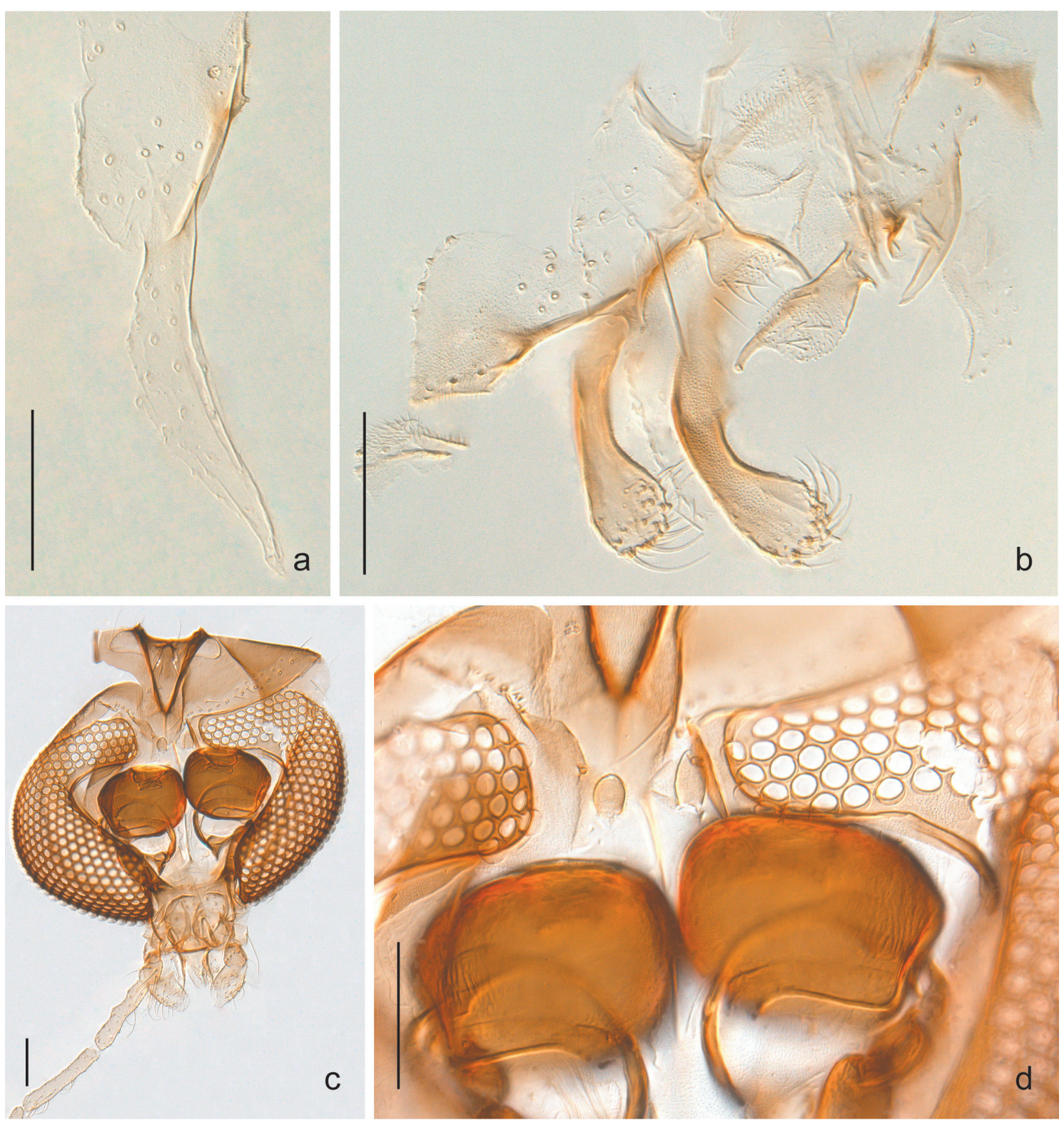

Figure 1. Chironomus (Benthalia) hamatus. Paratype male: a) gonocoxite and gonostylus (slightly crushed subapically); b) hypopygium remains; c) Head; d) Head section showing frontal tubercles and warts. Scale bars $=100 \mu \mathrm{m}$. 
Kieffer, Chaetolabis Townes and Lobochironomus Ryser, Wülker \& Scholl. Molecular phylogenies are inconclusive for the group placement of Benthalia (Martin et al. 2007 sub Lobochironomus dissidens $=$ Benthalia carbonaria), but indicate a closer relationship to species in Chironomus sensu stricto. Until conclusive data that are provided, preferably through molecular systematic studies with wide sampling of Chironomus species and relatives, we regard Benthalia as a subgenus of Chironomus.

\section{Cladopelma inflexum (Freeman, 1957)}

Chironomus (Cryptochironomus) inflexus Freeman, 1957: 403.

Cladopelma inflexum (Freeman, 1957), Freeman and Cranston (1980).

Material examined: Holotype male \& 1 paratype female (NHMUK), Sudan, Khartoum, x.1951, D. J. Lewis.

The species was listed as a new combination in Cladopelma Kieffer by Freeman and Cranston (1980), but later transferred to Cryptotendipes by Ashe et al. (1987) based on personal communication with P. S. Cranston. We have examined the male holotype (pinned specimen with hypopygium on separate celluloid strip) and a slide mounted female paratype (Fig. 2). The presence of small frontal tubercles (Figs 2c, d), male gonostyli with a narrow base (Fig. 2a) and setae ventrally on segment $\mathrm{X}$ of the female abdomen (Fig. 2b) points
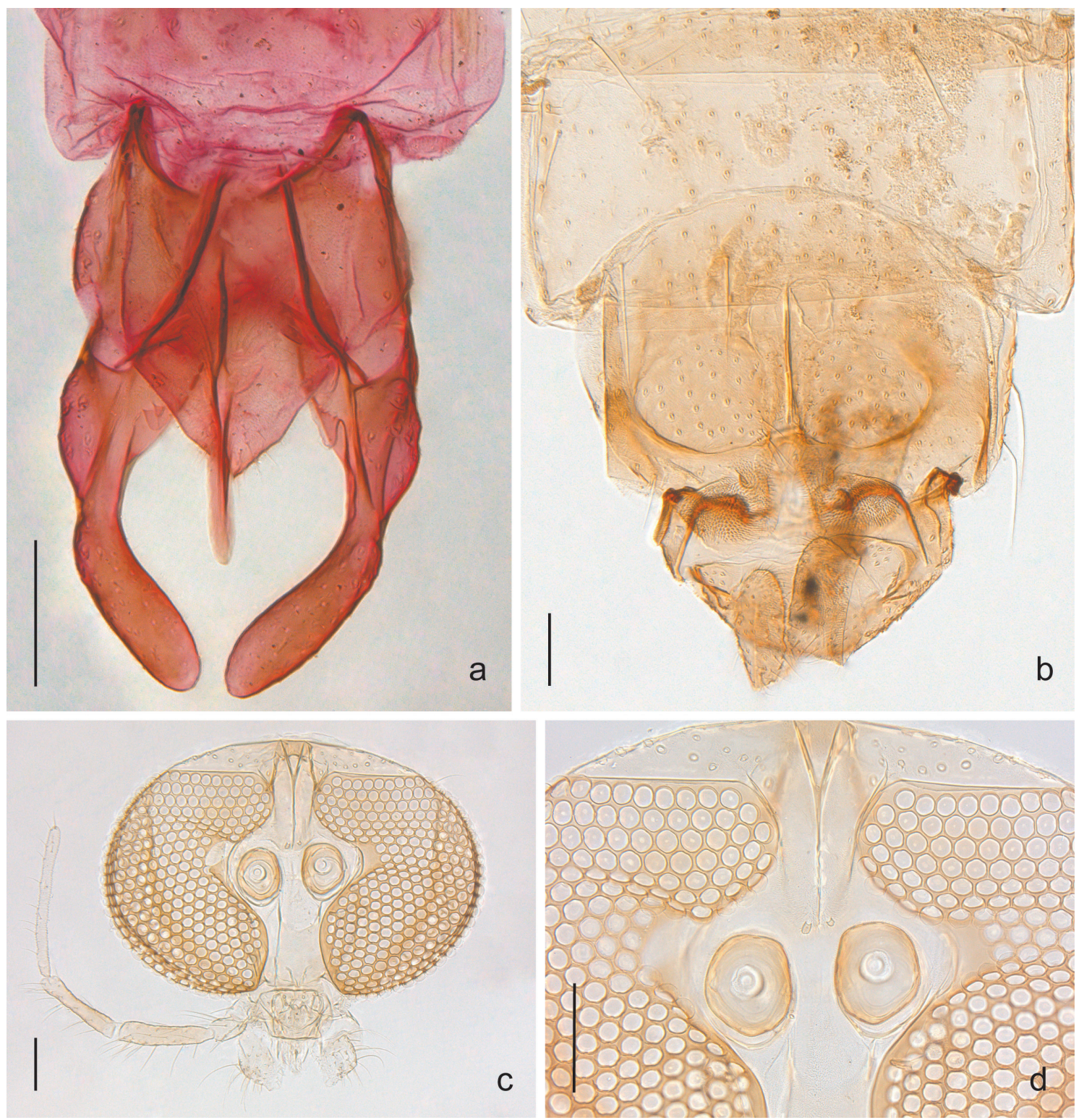

Figure 2. Cladopelma inflexum. a) holotype male hypopygium; b) paratype female genitalia; c) paratype female head; d) paratype female head section showing frontal tubercles. Scale bars $=100 \mu \mathrm{m}$. 
towards placement in Cladopelma. The gonocoxal appendages of the holotype can be interpreted as a small wart-like superior volsella above a weak lobe-like inferior volsella (Fig. 2a), but this is not a completely clear structure on both sides. The presence of an inferior volsella is not compatible with the present diagnosis of Cladopelma (Cranston et al. 1989, Yan et al. 2008), but more material of $C$. inflexum, including associated immatures, should be examined before eventual emendations to diagnostic characters of Cladopelma are made. The species is known as adults from Chad, Malawi, Niger and Sudan (Freeman and Cranston 1980, McLachlan 1975).

\section{Kiefferulus pruinosus (Freeman, 1961) comb. n.}

http://zoobank.org/0A207111-3F6B-4169-A6EB2CDDC478E839

Chironomus (Endochironomus) pruinosa [sic!] Freeman, 1961: 246.

Endochironomus pruinosus (Freeman, 1961), Freeman and Cranston (1980).

Material examined: Holotype male (MNHN), Madagascar Nord, Montagne d'Ambre 1000m,

\section{3.xi-4.xii.1958, B. Stuckenberg.}

The male holotype lacks frontal tubercles, has numerous setae on vein $\mathrm{R}$ in an otherwise bare wing (Fig. 3a), and has divided mid- and hind tibial combs, each with spur. Antenna with 11 flagellomeres and an AR of about 2.7. The hypopygium (Fig. 3b) lacks median tergite setae, has Y-shaped anal tergite bands, almost bare superior volsella, setose inferior volsella that is slightly expanded dorso-ventrally and gonostylus with slight subapical constriction. The species fits quite well in the definition of Kiefferulus Goetghebuer after the inclusion of Nilodorum Kieffer by Cranston et al. (1990). Indeed Freeman (1961) had discussed the similarity with Nilodorum in the original description, especially with regard to the appearance of the thorax (Fig. 3c). He chose not to place the species there due to the normally developed maxillary palps and the narrow inferior volsella, but these characters later have been argued not to be diagnostic at genus-level (Cranston et al. 1990). The shape of the superior volsella (Fig. 3b) is quite aberrant compared to other species in Kiefferulus, but we interpret this as a species-specific trait.

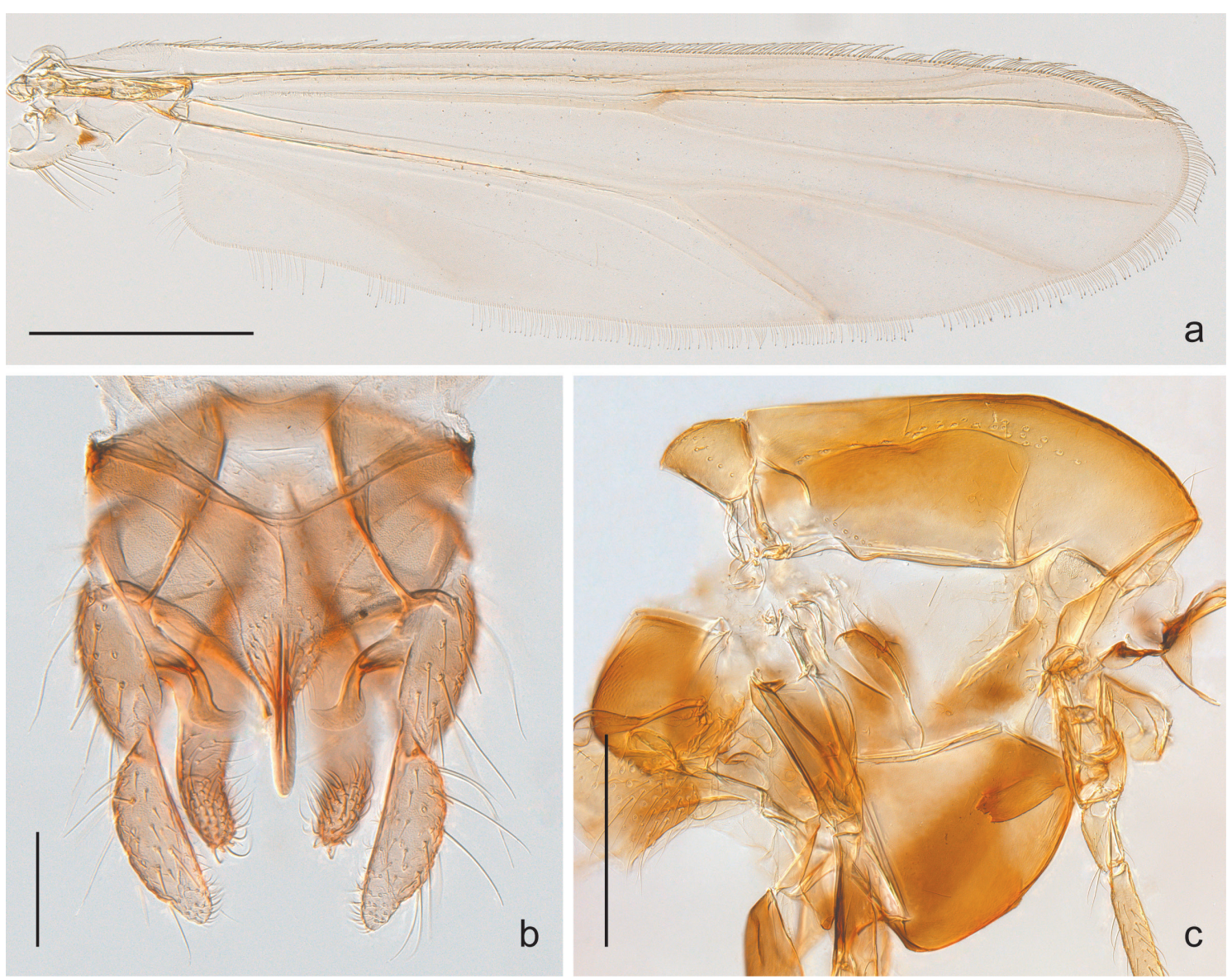

Figure 3. Kiefferulus pruinosus. Holotype male: a) wing, scale bar $=500 \mu \mathrm{m}$; b) hypopygium, scale bar $=100 \mu \mathrm{m} ; \mathrm{c})$ thorax, scale bar $=500 \mu \mathrm{m}$. 
Synendotendipes woodi (Freeman, 1957) comb. n.

http://zoobank.org/F6E9848E-4A3B-4A06-A2C344209379EA86

Chironomus (Endochironomus) woodi Freeman, 1957: 355.

Endochironomus woodi (Freeman, 1957), Freeman and Cranston (1980).

Material examined: Holotype male (NHMUK), Malawi, Ruo, 6.iv.1916, R. C. Wood; 2 males \& 1 female paratype as holotype; 1 paratype male (NHMUK) Uganda, Natadgidza?, v.1937, G. L. R. Hancock; 1 paratype male (NHMUK) Ni- geria, Zungeru, xi.1910, J. W. Scott-Macfie; 2 males (ZMBN) Ghana, Eastern Region, Bothi falls, at light, 14.x.1994, T. Andersen et al.; 1 male (ZMBN) Ghana, Western Region, Ankasa Game Production Reserve, Malaise trap \#10, 6-12. xii.1993, T. Andersen et al.

The examined material fits well with the definitions of Synendotendipes Grodhaus (as opposed to Endochironomus Kieffer) in lacking a tarsal beard in the adult male, lacking mid- and hind tibial spurs, and by having a very slightly broadened base of the superior volsella (Figs $4 a, b$ ). The species also has a head without frontal tubercles
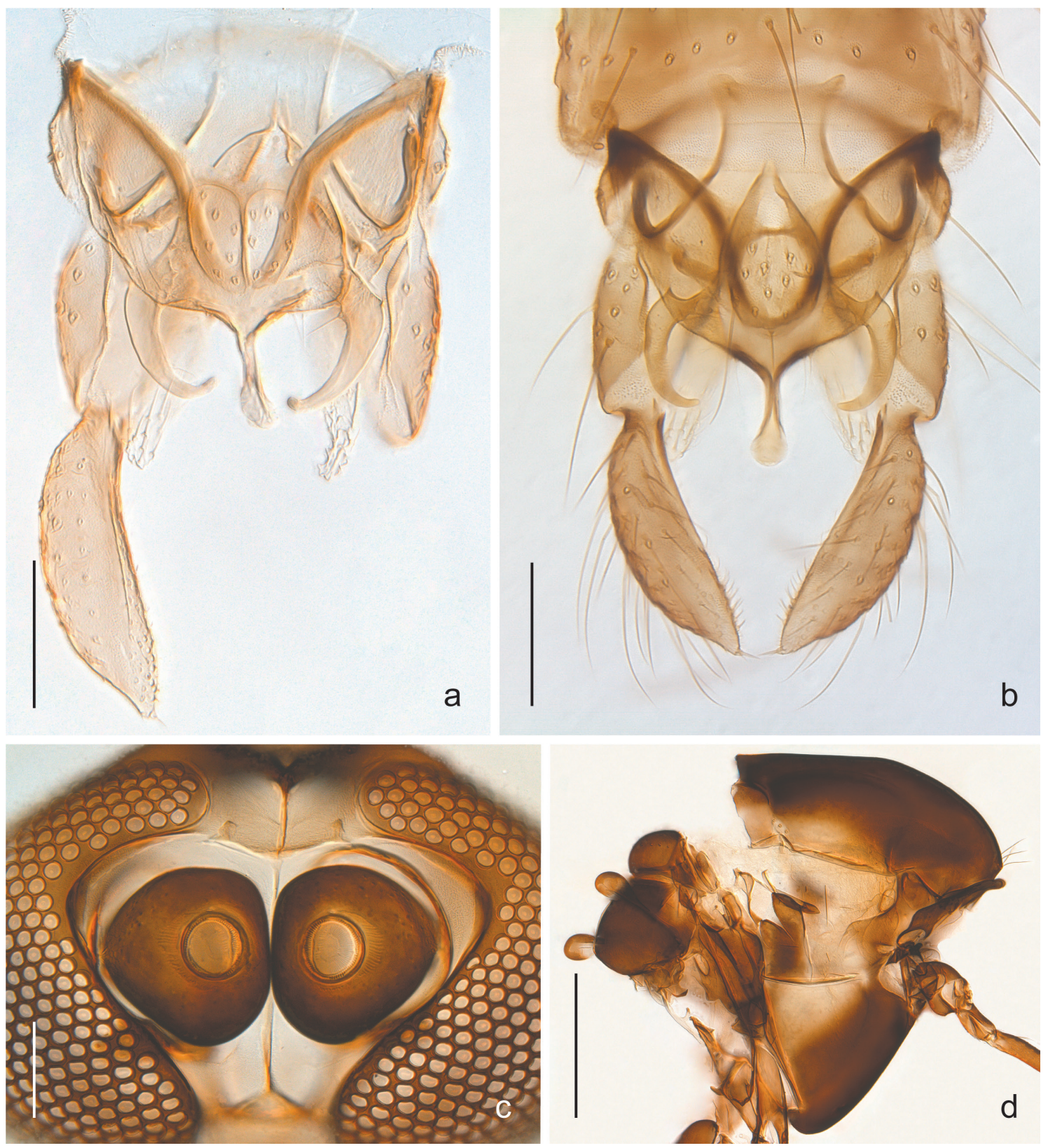

Figure 4. Synendotendipes woodi. a) paratype male hypopygium (Uganda); b) male hypopygium (Ghana); c) male head (Ghana); d) male thorax (Ghana). Scale bars a-c $=100 \mu \mathrm{m}$; scale bar $\mathrm{d}=500 \mu \mathrm{m}$. 
(Fig. 4c) and thorax with widely divided, but well developed antepronotal lobes (Fig. 4d) as is typical for Synendotendipes (Cranston et al. 1989).

\section{Acknowledgements}

We would like to thank Duncan Sivell (NHMUK), Christophe Daugeron (MNHN), Trond Andersen and Steffen Roth (both ZMBN) for organising loan of material. Thanks also to Pete Cranston, Martin Spies and Patrick Ashe for valuable input on the taxonomy of the treated species, and to Pete Cranston and John Epler for peer-reviewing the manuscript.

\section{References}

Ashe, P., Murray, D.A. and Reiss, F. 1987. The zoogeographical distribution of Chironomidae (Insecta: Diptera). - Annales de Limnologie 23: 27-60.

Cranston, P.S., Dillon, M.E., Pinder, L.C.V. and Reiss, F. 1989. The adult males of Chironominae (Diptera, Chironomidae) of the Holarctic region. Keys and diagnoses. In Wiederholm, T. (Ed.), Chironomidae of the Holarctic region. Keys and diagnoses. Entomologica scandinavica Supplement 34: 353-502.

Cranston, P.S., Webb, C.J. and Martin, J.O.N. 1990. The saline nuisance chironomid Carteronica longilobus (Diptera: Chironomidae): a systematic reappraisal. - Systematic Entomology 15: 401-432.

Ekrem, T., Ashe, P., Andersen, T. and Stur, E. in press. 35. Chironomidae (Non-biting midges). In Kirk-Spriggs, A.H. and Sinclair, B.J. (Eds.) Manual of Afrotropical Diptera. South African National Biodiversity Institute, pp. nn-nn.

Ekrem, T., Sublette, M.F. and Sublette, J.E. 2003. North American Tanytarsus I. Descriptions and keys to species in the eminulus, gregarius, lugens and mendax species groups (Diptera: Chironomidae). - Annals of the Entomological Society of America 96: 265-328.DOI: http://dx.doi. org/10.1603/0013-8746(2003)096[0265:NATI DA]2.0.CO;2

Epler, J.H., Ekrem, T. and Cranston, P.S. 2013. The larvae of Holarctic Chironominae (Diptera: Chironomidae) - Keys and diagnoses. In Andersen, T., Cranston, P.S. and Epler, J.H. (Eds.) Chironomidae of the Holarctic Region - Keys and diagnoses. Scandinavian Entomology Ltd, pp. 387-556.

Freeman, P. 1955. A study of the Chironomidae (Diptera) of Africa south of the Sahara. Part I.
- Bulletin of the British Museum (Natural History), Entomology 4: 1-67.

Freeman, P. 1956. A study of the Chironomidae (Diptera) of Africa south of the Sahara. Part II. - Bulletin of the British Museum (Natural History), Entomology 4: 285-366.

Freeman, P. 1957. A study of the Chironomidae (Diptera) of Africa south of the Sahara. Part III. - Bulletin of the British Museum (Natural History), Entomology 5: 321-426.

Freeman, P. 1958. A study of the Chironomidae (Diptera) of Africa south of the Sahara. Part IV. - Bulletin of the British Museum (Natural History), Entomology 7: 331-357.

Freeman, P. 1961. A collection of Chironomidae and Culicidae subfamily Dixinae (Diptera, Nematocera) from Madagascar. - Mémoires de L'Institut Scientifique de Madagascar 12: 238255.

Freeman, P. and Cranston, P.S. 1980. II. Family Chironomidae. In Crosskey, R.W. (Ed.), Catalogue of the Diptera of the Afrotropical Region. British Museum (Natural History), pp. 175-202.

Grodhaus, G. 1987. Endochironomus Kieffer, Tribelos Townes, Synendotendipes, n. gen., and Endotribelos, n. gen. (Diptera: Chironomidae) of the Nearctic Region. - Journal of the Kansas Entomological Society 60: 167-247.

Martin, J., Blinov, A., Alieva, E. and Hirabayashi, K. 2007. A molecular phylogenetic investigation of the genera closely related to Chironomus Meigen (Diptera: Chironomidae). In Andersen, T. (Ed.), Contributions to the Systematics and Ecology of Aquatic Diptera: A Tribute to Ole A. Scether. The Caddis Press, pp. 193-203.

McLachlan, A.J. 1975. The role of aquatic macrophytes in the recovery of the benthic fauna of a tropical lake after a dry phase1. - Limnology and Oceanography 20: 54-63.

Pinder, L.C.V. 1989. The adult males of Chironomidae (Diptera) of the Holarctic region - Introduction. In Wiederholm, T. (Ed.), The adult males of Chironomidae (Diptera) of the Holarctic region - Keys and diagnoses. Entomologica scandinavica Supplement 34: 5-9.

Shilova, A.I. 1980. K sistematike roda Einfeldia Kieffer (Diptera, Chironomidae). [On the systematics of the genus Einfeldia Kieffer (Diptera, Chironomidae)]. - Trudy Inst. Biol. vnutr. Vod Akad. Nauk SSSR 41: 162-191. 
Sæther, O.A. 1977a. Female genitalia in Chironomidae and other Nematocera: morphology, phylogenies, keys. - Bulletin of the Fisheries Research Board of Canda 197: 1-209.

Sæther, O.A. 1977b. Taxonomic studies on Chironomidae: Nanocladius, Pseudochironomus, and the Harnischia complex. - Bulletin of the Fisheries Research Board of Canda 196: 1-143.

Sæther, O.A. 1980. Glossary of chironomid morphology terminology (Diptera: Chironomidae). - Entomologica scandinavica Supplement 14: $1-51$.

Sæther, O.A. 2012. The Chironomus group (Diptera: Chironomidae) in Lake Winnipeg, Canada. - Zootaxa 3275: 1-19.DOI: http://dx.doi. org $/ 10.11646 / \% 25 x$
Sæther, O.A. and Spies, M. 2013. Fauna Europaea: Chironomidae. In de Jong, H. and Pape, T. (Eds.) Fauna Europaea: Diptera: Nematocera. Fauna Europaea version 2.6.2, http://www. fauna-eu.org/.

Yamamoto, M. and Yamamoto, N. 2014. Family Chironomidae. In Editorial Committee of Catalogue of the Insects of Japan (Ed.), Catalogue of the Insects of Japan. Volume 8 Diptera (Part 1 Nematocera - Brachycera Aschiza). Touka Shobo, pp. 237-362.

Yan, C.C., Jin, Z.H. and Wang, X.H. 2008. Cladopelma Kieffer from the Sino-Indian Region (Diptera: Chironomidae). - Zootaxa 1916: 4456.DOI: http://dx.doi.org/10.11646/\%25x

Article submitted 17. March 2016, accepted by Alyssa M. Anderson 26. May 2016, published 21. June 2016. 